\title{
Diferentes teorias marxistas de crise e diferentes interpretações da crise atual ${ }^{1}$
}

\author{
Francisco Paulo Cipolla ${ }^{2}$
}

\section{Resumo}

Este artigo apresenta criticamente diferentes interpretações da crise atual. Orientaram a seleção das várias contribuições a representatividade das teorias marxistas clássicas de crise e a importância das novas abordagens correspondentes aos novos fenômenos em desenvolvimento no capitalismo atual. O exame crítico dessas contribuições revela uma linha divisória entre aqueles que concebem a crise como tendo sido causada pelo afluxo dos lucros da produção para as finanças (Husson e Foster /Magdoff) e aqueles para os quais o aumento do crédito de consumo foi resultado de uma reestruturação dos fluxos de crédito das empresas, cada vez mais autônomas no mercado de dinheiro, às famílias assalariadas, cada vez mais dependentes do financiamento bancário. Essa linha divisória reflete a importância que o primeiro grupo adjudica à diminuição do ritmo de crescimento vis-à-vis os teóricos da School of Oriental and African Studies. A análise revela também que a atrofia da economia política leva a um abandono precoce da teoria bancária e financeira de Marx em favor dos instrumentos teóricos pós-keynesianos imediatamente disponíveis para o uso.

Palavras-chave: Teorias marxistas de crise; Taxa de lucro; Estagnação.

\section{Abstract \\ Different Marxist theories of crises and different interpretations of the current crisis}

This article is a critical survey of different interpretations of the 2007-2008 financial crises. They were chosen either because they represented classical Marxian views on crisis, such as the underconsumption or over-accumulation theories, or else because they were newly developed interpretations based on recent newly economic developments, as it is the case of the financial expropriation theory. The analysis reveals three main points of view. The first is that the cause of crisis is the stagnation of the economy and the ensuing transfer of profits from production to finance, process that caused the housing-financial bubble (Husson and Foster/Magdoff). The second view argues that it was the structural change in financial markets which led banks to increasingly rely on consumer credit as a profitable alternative to corporate financing which has become increasingly independent from bank sources (Lapavitsas and dos Santos). The third view argues that low rates of profit caused sluggish growth rates while governments tried to compensate for by promoting demand through cheap credit (Kliman). Finally, it is worth noticing that the incipient use of Marxian categories to the analysis of banking and finance leads systematically to the use of the postKeynesian theories immediately available thus reproducing its condition of underdevelopment.

Keywords: Marxian theories of crises; Rate of profit; Stagnation.

JEL E11.

(1) Trabalho recebido em 15 de junho de 2010 e aprovado em 23 de abril de 2011.

(2) Professor Titular do Departamento de Economia da Universidade Federal do Paraná (UFPR), Curitiba, PR, Brasil. E-mail: cipolla@ufpr.br.

Economia e Sociedade, Campinas, v. 21, n. 1 (44), p. 39-59, abr. 2012. 


\section{Introdução}

A crise econômica mundial iniciada no verão setentrional de 2007 gerou uma diversidade de contribuições no campo marxista de análise. Em que pese essa diversidade, as interpretações coincidem em que a crise teve como terreno preparatório a redução, a partir do final dos anos 1970, do ritmo de acumulação de capital $^{3}$, fenômeno contra o qual os governos fizeram o contrapeso através de políticas econômicas de incentivo ao crédito, particularmente o crédito direcionado ao consumo privado. A bolha imobiliária, ocorrida nos EUA, teria sido apenas o último capítulo de um conjunto de tentativas de contrabalançar o baixo ritmo de crescimento através de um processo de endividamento doméstico que serviu de base para uma lucrativa operação que engolfou praticamente todas as instituições da esfera financeira.

Este artigo analisa quatro diferentes tipos de interpretação da crise iniciada no ano de 2007. A primeira refere-se à visão estagnacionista associada à escola da Monthly Review, revista que teve início em 1949 e cujos primeiros editores foram Paul M. Sweezy (1910-2004) e Leo Huberman, este último falecido em 1968 e substituído por Harry Magdoff (1913-2006). A partir de 2000, o editor da Monthly Review passou a ser John Bellamy Foster. É a contribuição deste último conjuntamente com Fred Magdoff no livro The Great Financial Crisis o material de que se ocupará a parte relativa à interpretação subconsumista e estagnacionista da crise. A segunda contribuição a ser considerada é a de Costas Lapavitsas e Paulo dos Santos, professores da School of Oriental and African Studies, faculdade da London University, mais simplesmente conhecida como SOAS. De origem mais recente, a interpretação sugerida pelos proponentes dessa escola relaciona-se às transformações financeiras acorridas a partir dos anos 1980, transformações, essas, que ocasionaram o surgimento da relação de expropriação financeira da força de trabalho na forma da absorção de parcela crescente dos salários pelos juros e taxas bancárias. As contribuições de Costas Lapavitsas e Paulo dos Santos encontram eco em recente artigo de Makoto Itoh (2009), fato que nos leva a incluí-lo como partidário da visão de expropriação financeira.

A terceira visão acerca da crise atual relaciona-se aos proponentes de que, em última instância, ainda que não de forma imediata, a causa da crise foi a redução da taxa de lucro. O declínio da lucratividade seria a causa da diminuição do crescimento e das recorrentes tentativas de revertê-la através da expansão do crédito. A onda de endividamento familiar que desembocou na crise de 2007 teria sido apenas a mais recente e mais profunda das crises que se originaram dessas tentativas. A proposição central desta interpretação é a de que a lei de tendência de

(3) Esse fenômeno é documentado pelas visões de Kliman (2010, p. 16; 2009, p. 57) com referência à

economia dos EUA; por Husson (2010, p. 21) para a economia francesa, assim como para a economia estadunidense (p. 22) e por Foster e Magdoff (2009, p. 133) para os EUA. 
queda da taxa de lucro teria sido verificada do pós-guerra até o final dos anos 1980 e que o neoliberalismo não teria sido capaz de revertê-la. Essa é a visão de Andrew Kliman, que será o foco principal de nossa análise ${ }^{4}$.

A quarta visão é a de Husson cuja interpretação da crise se baseia justamente na convicção, diametralmente contrária à de Kliman, de que a causa da crise foi precisamente a recuperação da taxa de lucro resultante do aumento da taxa de exploração do trabalho, fato que teria impedido a recuperação econômica devido à restrição da demanda proveniente da redução do poder de compra dos salários.

Uma vez que todas essas interpretações situam a crise no contexto da relativa estagnação da economia, a segunda parte deste artigo procura explicitar as diferentes razões que esses autores aduzem para o entendimento da redução do ritmo de crescimento ocorrido durante o período que se estende dos anos 1980 até os dias de hoje. A segunda parte do artigo tem como objetivo apresentar as várias interpretações da crise. A terceira parte desenvolve a crítica às várias interpretações analisadas no presente trabalho. A quarta parte apresenta comentários adicionais, além de um resumo dos resultados obtidos e conclusões pertinentes.

\section{As diferentes visões da estagnação}

A escola estagnacionista da Monthly Review, continuada, agora, pelas contribuições de Fred Magdoff e John Bellamy Foster, remete às análises sugeridas por Paul Baran e Paul Sweezy na década de 1960. É precisamente a eles que recorrem Foster e Magdoff (2009) para explicar a simbiose entre estagnação e financeirização da economia, ponto focal de suas visões sobre a crise atual. Em Sweezy (1973), a tendência ao subconsumo e, portanto, à estagnação como "norma para a qual tende a produção capitalista" (p. 246) era derivada a partir da suposição de que investimento e consumo capitalista cresceriam como proporção da renda e que, portanto, a participação dos salários deveria cair. Como também supunha que a proporção do consumo capitalista na renda cairia, Sweezy deduziu um aumento da proporção do investimento na renda. Supondo que a produção de meios de consumo fosse proporcional ao crescimento do investimento, Sweezy inferiu que a oferta de meios de consumo cresceria à frente da demanda de meios de consumo, causando um excesso crônico de capacidade. Essa é a teoria subconsumista e estagnacionista de Sweezy. O erro teórico, tal como apontado por Shaikh (1978), consiste em considerar o departamento I como insumo do

(4) Brenner (2009) também considera o efeito negativo da diminuição da lucratividade na gestação da crise ora em curso. Porém, para ele, essa redução não foi efeito da lei tendencial de queda da taxa de lucro, mas, sim, do aumento da concorrência mundial.

Economia e Sociedade, Campinas, v. 21, n. 1 (44), p. 39-59, abr. 2012. 
departamento II e, portanto, a economia capitalista como tendo por objetivo a produção de bens de consumo.

Para Baran e Sweezy a tendência da economia capitalista moderna à estagnação relaciona-se à emergência dos monopólios e oligopólios. No seu livro de 1968, Monopoly Capital, Sweezy e Baran argumentam que os oligopólios baniram a concorrência de preços (p. 58-59). Com isso, a teoria geral de preços apropriada a essa economia passou a ser "a teoria tradicional dos preços de monopólio clássica e neo-clássica", agora erigida ao patamar de caso geral e não mais especial (p. 59). Somada à tendência das grandes corporações a diminuir constantemente os custos, os autores derivam a tendência ao contínuo aumento da margem de lucro sobre o produto bruto (p. 67). A partir dessa análise, concluem que a lei de tendência de queda da taxa de lucro deve dar lugar à lei de tendência de aumento da massa e da parcela de lucro (p. 72). Como os dividendos, a partir dos quais a classe capitalista efetua o seu consumo, aumentam com uma defasagem em relação ao aumento dos lucros, o consumo capitalista cai como proporção do excedente. Isso significa que teria que crescer continuamente a proporção do excedente destinada ao investimento. Mas os autores não vêm sentido nisso, pois "significaria que um volume cada vez maior de bens de capital seriam produzidos com o único fim de produzir mais bens de capital no futuro. $\mathrm{O}$ consumo seria uma proporção decrescente do produto e o aumento do estoque de capital não teria nenhuma relação com o aumento do consumo" (p. 81). "Mais cedo ou mais tarde o excesso de capacidade seria tão grande que desencorajaria investimentos ulteriores" (p. 82). Essa é, pois, a tendência à estagnação segundo Baran e Sweezy: a retração dos investimentos e, portanto, da renda e do emprego é provocada pela própria tendência ao aumento dos lucros gerados pelos oligopólios. Do mesmo modo, para Foster e Magdoff (2009), o capitalismo monopolista gera volumes de lucro que não podem ser reinvestidos sob pena de deprimir os preços e as margens de lucro. A demanda é, pois, incapaz de ocupar toda a capacidade instalada, fato que reduz o ritmo dos investimentos (p. 15), gerando, assim, a estagnação da economia própria da concepção do capitalismo monopolista da Monthly Review ${ }^{5}$.

Foster e Magdoff seguem a tradição de Keynes-Kalecki-Steindl, para quem o capitalismo é incapaz de autoexpansão, contrariamente a Marx, para quem a acumulação e o crescimento são gerados endogenamente. Para esses autores,

(5) Referindo-se a Baran e Sweezy (1968), Foster e Magdoff argumentam que "O problema para eles era que a enorme produtividade dos oligopólios somada ao mecanismo de preços próprio dos oligopólios gerava uma massa de excedente que não podia ser absorvida pelos gastos de consumo e investimento. A demanda efetiva era insuficiente mesmo quando a ela se somava o gasto público. O sistema se tornou, portanto, dependente de montantes crescentes de desperdício na forma de gastos militares, propaganda, finanças especulativas, etc. No entanto, esses estímulos externos se mostraram inadequados, uma vez que eram necessários montantes cada vez maiores para manter a economia de pé" (Foster; Magdoff, 2009, p. 15). 
fatores externos são necessários para manter o crescimento da economia, sejam eles os gastos do estado, os fatores de desenvolvimento de Kalecki, as inovações de Schumpeter ou, no caso em pauta, as bolhas especulativas através das quais o capitalismo logra alimentar o consumo durante um certo tempo, a exemplo da bolha especulativa imobiliária que conduziu à crise financeira mundial.

A "escola" da expropriação financeira não apresenta nenhuma análise específica relativa à diminuição da taxa de crescimento da economia mundial a partir dos anos 1980, exceto que, teriam tido papel fundamental nesse processo, tanto a diminuição do investimento quanto a concentração da renda. Dos Santos (2009) refere-se à diminuição do investimento de capital fixo como proporção do PNB a partir de meados dos anos 80. Somada à diminuição da participação na renda dos 9 percentis inferiores de renda, dos Santos sugere o aparecimento de um problema de amortecimento do ritmo de crescimento da demanda (p. 13). Esses dois aspectos serão cruciais para explicar tanto a procura dos bancos por novas fontes de demanda de crédito, alternativas à diminuição da demanda industrial por crédito bancário, quanto a fragilidade crescente do poder de compra das famílias assalariadas e sua exposição às práticas induzidas pelos bancos de consumo à base de endividamento. Para Lapavitsas (2009) a financeirização e seu componente principal, a expropriação financeira, desenvolvem-se num contexto de "dudoso crecimiento de la productividad" e de medíocre desempenho da acumulação real. É nesse ambiente de relativa estagnação que "a classe capitalista encontrou novas fontes de lucro nos mecanismos financeiros modernos" (p. 34).

Para Husson $(2010$, p. 5), a causa da redução relativa do processo de acumulação está na "rarefação de ocasiões de investimento rentável". Como a taxa de lucro aumentou acentuadamente a partir dos anos 1980, essa rarefação de oportunidades rentáveis de investimento deve se explicar, em parte, pelo fato de que o aumento da lucratividade tenha sido obtido através do aumento da exploração do trabalho e, portanto, através da redução do poder de compra dos trabalhadores. Desse modo, abre-se uma brecha crescente entre taxa de lucro que se recupera com as práticas antilaborais do neoliberalismo e taxa de acumulação que deixa de acompanhar o crescimento da lucratividade ${ }^{6}$. O crescimento dos lucros às custas do crescimento dos salários teria gerado um problema de demanda efetiva que, por sua vez, teria desacelerado a acumulação. Desse modo, a análise parece situar-se nos mesmos marcos teóricos do estagnacionismo subconsumista, uma vez que explica a estagnação a partir da fraqueza da demanda de consumo proveniente dos salários.

(6) "O fato de que uma parte crescente da mais-valia não seja acumulada é um sintoma da crise sistêmica do capitalismo; a rarefação de oportunidades de investimento lucrativo faz com que parte da mais-valia seja direcionada à esfera financeira a fim de alimentar o consumo dos rentiers ou dar impulso às bolhas especulativas" (Husson, 2010, p. 5, tradução do autor).

Economia e Sociedade, Campinas, v. 21, n. 1 (44), p. 39-59, abr. 2012. 
Em contraste com a visão de Husson, para Kliman, a taxa de lucro não logrou se recuperar durante o período neoliberal. Para ele, o comportamento letárgico da acumulação capitalista se explica pelo fato de que, bloqueado pela intervenção do Estado, o mecanismo normal de saneamento da lucratividade por meio da destruição de capital, própria dos períodos de crise, não pode funcionar, fato que teria impedido a recuperação da taxa de lucro para patamares acima da taxa de lucro de longo prazo e possibilitado a reedição de um novo boom. Na falta do saneamento da lucratividade por meio da crise, a taxa de lucro manteve-se "cronicamente muito baixa para permitir uma taxa de crescimento vigorosa" (Kliman 2009 , p. 2). De acordo com a sua análise empírica, a taxa de lucro teria permanecido praticamente no mesmo patamar entre os pontos baixos de $1982 \mathrm{e}$ 2001. Ao contrário de Husson, para quem lucros e investimentos se afastam num comportamento em tesoura a partir dos anos 1980, para Kliman, a taxa de acumulação apresenta, ao longo do tempo, uma evolução paralela à taxa de lucro. Desse modo, tal qual a taxa de lucro, a taxa de acumulação se manteve igualmente estagnada.

O objetivo desta parte foi o de apresentar as várias visões referentes ao comportamento pouco dinâmico da acumulação; comportamento, esse, que estaria na base das políticas econômicas de incentivo ao consumo através do crédito. $\mathrm{Na}$ próxima sessão serão analisadas as explicações de cada uma dessas visões para o processo de gestação da crise.

\section{As interpretações da crise}

Entre as visões apresentadas acima, duas delas lançam mão da noção de financeirização como processo conexo à estagnação. São elas: as visões da escola da Monthly Review, de um lado, e de Husson, de outro. Suas posições são parecidas: os lucros que não encontram possibilidades de acumulação produtiva são canalizados para o sistema financeiro na forma de aplicações financeiras.

Os marxistas da SOAS também se referem ao termo financeirização, mas, para eles, o traço fundamental da financeirização é, de um lado, o desenvolvimento do mercado de capitais e as novas fontes de financiamento que ele permite e, de outro, o aprofundamento do consumo mediado pelas instituições bancárias e financeiras.

Segundo Lapavitsas (2009) as tendências contemporâneas de aumento dos mercados abertos de capitais, através dos quais as empresas industriais e comerciais se abastecem de capital-dinheiro, contrasta com as teses marxistas clássicas de crescente domínio dos bancos sobre a indústria (p. 78). Ao contrário, sugere Lapavitsas, a crescente independização das empresas em relação ao crédito bancário forçou os bancos à busca de fontes alternativas de ganhos na renda 
pessoal dos trabalhadores e na forma de comissões e taxas relativas às diversas atividades de intermediação financeira às quais tiveram acesso com a progressiva desregulamentação da atividade bancária.

Para Lapavitsas, a relação entre setor financeiro e empresas é uma relação entre iguais tanto do ponto de vista da informação quanto do ponto de vista da força relativa, sendo esta última permitida pela existência de alternativas de financiamento. Essa simetria não existe na relação entre bancos e indivíduos. Estes últimos foram progressivamente expostos a necessidades sociais não providas pelo Estado (p. 43) e se viram forçados ao recurso do financiamento bancário em condições de desvantagem de força, pela falta de alternativas e de informação (p. 44). É nessas condições que se desenvolve o elemento central da financeirização que é a expropriação de parte da renda da classe trabalhadora na forma de juros bancários, processo relacionado, segundo Lapavitsas, à crescente utilização, pelas grandes empresas, do mercado livre de crédito como alternativa ao crédito bancário e à consequente busca dos bancos por fontes de lucros alternativos. A escala que atinge a expropriação financeira, no entanto, impede a análise de risco tradicional baseada na relação cliente/banco e na informação individual. Ao contrário, a escala da expropriação financeira mobilizou formas de avaliação de risco baseadas em métodos estatísticos e matemáticos. No caso da bolha imobiliária e a concomitante expansão das hipotecas subprime, "los préstamos se concedian cuando se superaba un umbral deliberadamente bajo" (Lapavitsas, p. 47). Ademais, para evitar os requerimentos de capital próprio, os bancos hipotecários passaram a vender as hipotecas a bancos de investimento, recuperando o capital emprestado, aumentando a rotação do seu capital e ampliando a gama dos seus clientes para as camadas mais pobres (p. 51).

Uma vez que a fonte mais dinâmica de crescimento dos lucros bancários passou a ser a apropriação financeira de parte dos salários, os bancos tomaram a si a tarefa de expandir continuamente o crédito ao consumo, notadamente o crédito imobiliário. O resultado foi a transformação de uma crescente fração da renda pessoal em capital monetário bancário com o que os bancos puderam expandir ainda mais a base de operações de crédito. "De acordo com dados da Reserva Federal a porcentagem média da renda pessoal disponível utilizada para servir à dívida subiu consistentemente de 5.6\% em 1986 para 19.3\% em junho de 2007" (Lapavitsas, 2007). O próximo passo foi a formação das SIVs, Special Investment Vehicles, entidades cujo objetivo era permitir a operação de aquisição de títulos lastreados em hipotecas e outras dívidas sem a necessidade de cumprir as regras de Basle II referentes aos requerimentos de capital próprio compatíveis com investimentos de risco. Com essas entidades, os bancos puderam adquirir CDOs, Collaterized Debt Obligations, títulos de dívida que ofereciam um "excelente rendimiento" (Lapavitsas, 2009, p. 52). 
As compras de CDOs eram financiadas pela emissão de títulos de dívida de curto prazo de modo que essas instituições estavam fortemente alavancadas. Assim, quando as hipotecas subprime começaram a fazer água, essas instituições já não puderam levantar fundos no mercado de dinheiro para rolar a dívida de curto prazo. Tiveram, então, que se voltar para seus próprios bancos que, por sua vez, face às perdas de capital, foram forçados a paralisar o crédito.

A reorientação do crédito bancário ao crédito de consumo é extensivamente documentada por dos Santos (2009). O aumento do peso da dívida sobre o orçamento das famílias mostra que, apesar de ser um fenômeno generalizado entre os vários percentis da distribuição da renda, o maior aumento foi verificado entre os $20 \%$ mais pobres, subindo de $87,5 \%$ em 1989 para 285,5\% em 2007 (tabela 3, p. 10). Como reflexo dessa reorientação do crédito, os lucros derivados do crédito de consumo aumentaram como proporção dos lucros bancários totais (p. 8). Assim, para dos Santos (2009), a crise atual se iniciou como uma crise bancária moderna, envolvendo condições que não existiam nas crises bancárias anteriores. Sua base foi o financiamento às famílias para aquisição de casa própria, o aumento do preço das casas decorrente do aumento da demanda, a sanção do aumento do crédito imobiliário pelo aumento de preços das casas, até a derrocada final. Dos Santos (p. 16) argumenta que o significado social do endividamento é muito diferente quando se compara o capital e a força de trabalho. No crédito ao capital, argumenta, tem-se uma relação entre iguais já que ambos são capitalistas e buscam obter a valorização do seu capital. Contrariamente a isso, o propósito da força de trabalho não é o aumento do valor (p. 18). Os trabalhadores foram forçados ao endividamento devido à estagnação dos salários $\mathrm{e}$ ao caráter mercantil das necessidades sociais de moradia, saúde e educação. A compulsão à dívida dá à conversão de parte dos salários em lucros bancários, através do pagamento de juros, o caráter de expropriação financeira. É esse caráter compulsório do endividamento que explica a alta rentabilidade associada a esse tipo de crédito. Assim, a natureza privada da provisão de serviços essenciais juntamente com a estagnação dos salários levaram a um espetacular incremento do peso da dívida relativo à renda disponível das famílias de $60 \%$ circa no início da década de 1980 para níveis ao redor dos $130 \%$ na vigília da crise.

Para Foster e Magdoff (2009), a crescente predominância financeira resulta da tendência estagnacionista da economia nos termos desenvolvidos por Sweezy (1973) e por Sweezy e Baran (1968), tal como apresentado na seção anterior. $\mathrm{O}$ subconsumo causado tanto pela diminuição dos salários na renda quanto pela redução relativa do consumo capitalista à medida que os lucros aumentam levam a um enfraquecimento da demanda de bens de consumo. A redução da demanda de bens de consumo causa uma redução na utilização da capacidade produtiva instalada, fato que reduz o nível de investimentos. 
Na versão "monopolista", a tese estagnacionista postula que a crescente massa de lucros obtida com o aumento contínuo da produtividade não pode ser utilizada para a expansão da capacidade produtiva sob pena de redução de preços e de margens de lucro. Assim, parte considerável dos lucros é utilizada na compra de produtos financeiros. A financeirização é o contínuo fluxo de lucros que se desprende da esfera produtiva em busca de valorização financeira como $D-D$ ', algo aproximado à reprodução simples com uso financeiro da mais-valia.

Nesse processo, parte importante do reduzido crescimento advém do efeito riqueza pelo qual a valorização financeira logra aumentar o consumo daqueles que se enriquecem no bojo da bolha (p. 81). É citado o artigo de Sweezy ${ }^{7}$ no qual o autor sugere que se antes as explosões financeiras e especulativas resultavam da fase expansiva do ciclo econômico, agora, ao contrário, é a estagnação que leva aos processos especulativos e às crises financeiras. Como apontado por Shaikh (1978) a visão subconsumista partilha da ideia de que o consumo regula a produção como um todo já que os meios de produção constituem apenas meios de produção de meios de consumo. Ou seja, o departamento produtor de meios de produção é concebido como um insumo do departamento produtor de meios de consumo (p. 231). Assim, a concentração da renda que resultou da diminuição do ritmo de acumulação de capital e da redução dos salários durante o período neoliberal junto com a diminuição da renda dos capitalistas devotada ao consumo levou ao clássico excesso de produção de meios de consumo cuja única forma de escoamento foi através do crédito ao consumo (Foster; Magdoff, 2009, p. 28), fato que explica a quase duplicação, no período entre 1980 e 2005, da razão entre dívida de consumo e renda disponível, e a consequente deterioração das finanças das famílias estadunidenses; deterioração, essa, documentada pelo aumento do serviço da dívida como porcentagem da renda (tabela 1.3, p. 32) e pelo aumento da incidência de famílias inadimplentes (tabela 1.4, p. 33), especialmente entre os dois percentis mais baixos da renda.

Foster e Magdoff são enfáticos: é a estagnação devido ao excesso de capacidade e à falta de oportunidades lucrativas de investimento a causa da financeirização e não o contrário como argumentam "os trabalhos recentes de alguns economistas radicais nos Estados Unidos" (p. 106). Segundo eles, a financeirização resulta do aumento do excedente incapaz de encontrar oportunidades rentáveis na produção. É esse excedente canalizado para o setor financeiro o que caracteriza a financeirização. Foster e Magdoff citam artigo de Sweezy publicado na Monthly Review de maio de 1995 cujo título é "Economic Reminiscences". Sweezy diz: "A indústria privada é lucrativa mas não tem incentivo para investir; daí a estagnação do investimento produtivo. No entanto, as

(7) Trata-se de "The triumph of financial capital", conferência proferida por Sweezy e publicada no número de junho de 1994 da Monthly Review.

Economia e Sociedade, Campinas, v. 21 , n. 1 (44), p. 39-59, abr. 2012. 
grandes corporações e seus acionistas vão bem e procuram expandir seu capital aplicando o dinheiro no mercado financeiro que, por sua vez, responde absorvendo somas crescentes de investimento e criando novos e atrativos tipos de instrumentos financeiros" (Sweezy apud Foster; Magdoff, 2009, p. 105). Argumento idêntico, escrito de próprio punho, encontra-se nas páginas 79 e 80 do livro The Great Financial Crisis. Ali, Foster e Magdoff concluem: "O resultado foi a especulação financeira explosiva que persiste há décadas” (p. 80).

A análise se assenta na ideia de que, com o excesso de capacidade e a estagnação do investimento, a economia passou a depender cada vez mais do consumo. Os autores observam que, somente nos meses de outubro a dezembro de 2005 , foi adicionado ao estoque da dívida imobiliária uma soma de $\$ 1,11$ trilhões. Mas advertem que uma economia com alta exploração do trabalho, salários estagnados e poucas oportunidades de investimento não poderia manter $\mathrm{o}$ crescimento exceto através de bolhas especulativas. Nas condições de alto endividamento imobiliário relativamente ao valor dos imóveis, razão que se denomina home equity, qualquer amortecimento no preço das casas ou, alternativamente, um aumento dos serviços relacionados à dívida hipotecária poderiam significar o fim da bolha especulativa. Nesse artigo de maio de 2006, capítulo primeiro do livro, dizem com acurada previsão: "De fato, com o declínio do preço das casas durante quatro meses consecutivos e o ritmo de vendas em queda de 10,5\% em fevereiro, o maior declínio em quase uma década, é possível que estejamos diante do fim da bolha" (p. 36).

Mas qual foi o elo entre a análise estagnacionista e a onda especulativa imobiliária? A drástica redução das taxas de juros junto com as mudanças nos requerimentos de reservas bancárias de capital redirecionou os fluxos financeiros da Bolsa, em baixa após a debacle de 2000, para o mercado imobiliário. A partir desse ponto, a descrição da bolha imobiliária segue as fases sugeridas por Kindleberger: "um novo produto; expansão de crédito; febre especulativa; agonia; colapso e pânico"8. A securitização das hipotecas, a criação das SIVs por parte dos bancos, o financiamento da aquisição de MBS (Mortgage Backed Securities) e CDOs por meio da emissão de papéis comerciais, o rápido crescimento do mercado de Credit Default Swaps (p. 95) até alcançar a fase especulativa na qual o aumento da dívida para a compra de ativos financeiros passou a se basear no aumento dos preços dos ativos subjacentes, isto é, o preço das casas. Neste ponto, caracterizam o processo como Ponzi Finance com referência à análise de Minsky (p. 97).

Para Husson (2010), os últimos 50 anos se dividem em duas partes: a primeira, que se estende de 1960 a 1982, na qual a taxa de lucro decresce, e a

(8) “... a novel offering, credit expansion, speculative mania, distress, and crash/panic” (p. 94). 
segunda, que cobre o período de 1982 até 2008, em que a taxa de lucro se eleva. Esse comportamento se verifica tanto para os EUA quanto para as três maiores economias europeias (Alemanha, França e Inglaterra). Parte da recuperação da taxa de lucro a partir dos anos 1980 é explicada pelo aumento da taxa de exploração da força de trabalho, com o que a taxa de lucro reverte a contínua redução ocorrida a partir de 1960 (p. 3). A reversão da tendência de queda em tendência de alta da lucratividade, segundo o título irônico do seu artigo de 2010, deve-se ao aumento da taxa de exploração da força de trabalho. Em entrevista de julho de 2008, Husson diz: "O decréscimo da parcela salarial possibilitou um espetacular aumento da taxa média de lucro a partir da metade dos anos oitenta". No entanto, "a massa crescente de mais-valia não foi acumulada, mas principalmente distribuída na forma de rendas financeiras" (Husson 2008, p. 1). Tornada inviável pela própria redução do poder de compra dos salários, a acumulação deixou de acompanhar o grau de lucratividade, abrindo um gap crescente com o passar do tempo. Assim, a separação entre aumento da lucratividade e diminuição do ritmo dos investimentos é causada pelo fato de que o aumento da lucratividade foi obtido através de um aumento da taxa de exploração da força de trabalho. A redução relativa da demanda proveniente dos salários teria tornado não rentável o reinvestimento de parte da mais-valia obtida pela maior exploração do trabalho. Husson considera esse crescente gap entre taxa de lucro e taxa de acumulação um indicador do grau de financeirização da economia, já que aponta o grau no qual a mais-valia deve buscar formas financeiras de valorização. A parte da mais-valia que não é acumulada é reciclada na financeirização, e essa reciclagem tem o caráter funcional de substituir a falta de demanda a partir dos salários. Essa substituição se dá na forma do consumo dos rentiers e das bolhas especulativas (p. 5) ${ }^{9}$.

A crise, para Husson, resulta, portanto, não de uma redução da lucratividade, mas, sim, de sua elevação ocorrida no período neoliberal. Apesar da intrincada batalha empírica travada entre Husson e Kliman, a divergência fundamental é claramente teórica. Husson considera a lei da tendência de queda da taxa de lucro, tal como expressa por Marx, como equivocada (p. 18). Segundo ele, a formulação de Marx se ressente da não consideração do efeito da produtividade sobre o valor dos meios de produção e sobre a taxa de exploração da força de trabalho. Como a produtividade deprime o valor dos meios de produção enquanto, ao mesmo tempo, aumenta a taxa de mais-valia, a taxa de lucro não tem motivo necessário para decrescer com o decorrer do tempo. Além do mais, argumenta ele,

(9) "Quando a taxa de lucro aumenta em detrimento dos salários sem recriar condições lucrativas de investimento, as finanças passam a ocupar o papel funcional de criar fontes de demanda alternativas à demanda dos assalariados" (Husson 2008, p. 2). Aqui,parece haver um lapso por parte de Husson, pois grande parte do crescimento no período do boom imobiliário se deveu exatamente ao consumo dos trabalhadores e, portanto, não se configura como alternativa à demanda dos assalariados.

Economia e Sociedade, Campinas, v. 21, n. 1 (44), p. 39-59, abr. 2012. 
a composição orgânica não tem porque crescer, pois os meios de produção são continuamente barateados pelo aumento da produtividade ${ }^{10}$.

Kliman $(2009,2010)$ argumenta que um dos aspectos centrais da teoria da crise de Marx é o processo de destruição do capital, processo, esse, que restaura a lucratividade e prepara as condições para a reprodução do ciclo econômico. Não foi esse o caso a partir dos anos 1980. Ao invés de permitir o processo de destruição de capital, o Governo procurou compensar o baixo nível de crescimento através do estímulo ao endividamento. Seus cálculos empíricos da taxa de lucro se contrapõem à ideia de que o período neoliberal teria logrado obter uma recuperação da lucratividade. O cálculo, a custos históricos, entre os pontos de baixa dos anos de 1982 e 2001, mostra que ela se manteve virtualmente constante (12,1 e $11,9 \%$, respectivamente). Kliman calcula também a taxa de lucro a custos correntes, deflacionando o estoque de capital fixo e a massa de lucro pelo índice de preços do GDP americano (Gross Domestic Product) em contraste com Husson, que deflaciona o estoque de capital fixo pelo índice de preços dos meios de produção; índice, esse, que, segundo Kliman, foi maior do que o índice do GDP no período de análise, fato que teria causado uma subestimação do valor, a custos correntes, do estoque de capital fixo e, portanto, um aumento da estimativa de lucratividade. Segundo os cálculos de Kliman a taxa de lucro não se recuperou nas décadas de 1980 e 90 . No entanto, a mesma subiu decisivamente em meados da primeira década do século $\mathrm{XXI}^{11}$. Procura, então, traçar o elo intermediário entre esse comportamento da taxa de lucro e a crise, argumentando que o decréscimo da taxa de lucro não é a causa imediata da crise. Esse decréscimo, no entanto, provoca um período de especulação no qual os capitalistas tentam compensar o decréscimo da rentabilidade através de ganhos financeiros. $O$ aumento do endividamento que acompanha esse período de especulação leva à crise, assim que as dívidas se tornam mais pesadas do que a capacidade de pagá-las (p. 31). O aumento da taxa de lucro a partir de 2004 é, para ele, o efeito desse processo de reação à baixa da lucratividade, mas constitui, ao mesmo tempo, a preparação da crise que se abateu sobre a economia dos EUA e do mundo.

A sua proposição é que a taxa de lucro efetiva decresce para o nível da taxa de lucro de longo prazo, definida, por ele como a taxa de lucro incremental, $\Delta m / \Delta C$, onde $\Delta m$ é o incremento da massa de mais-valia e $\Delta C$ é o incremento do capital. A taxa incremental de lucro é uma magnitude mais ou menos constante, girando próxima dos $4 \%$ em todo o pós-guerra (p. 74). No processo cíclico, devido

(10) Para visões modernas e contrárias a Husson sobre esse assunto, ver Shaikh (1990) e Yaffe (1972).

(11) Joshua (2009) apresenta resultados similares aos de Kliman no que tange à ausência de recuperação da taxa de lucro a partir do começo da década de 1980. Apesar da recuperação inicial, esta se interrompe no início dos anos 90, de modo que a taxa de lucro média das corporações não financeiras dos EUA no período 2002-2008 $(9,9 \%)$ se situa no mesmo patamar da taxa de lucro média do período 1982-1992 (9.9\%). 
à destruição de capital que precede o início do novo período de expansão, a taxa de lucro efetiva situa-se acima da taxa de lucro de longo prazo. À medida que o boom se desenvolve, a taxa de lucro efetiva começa a convergir para a taxa de lucro incremental. A menos que uma nova crise permita o saneamento da lucratividade através da destruição de capital, a economia patinará num patamar de baixa lucratividade e baixo crescimento. Foi o que ocorreu no período neoliberal, no qual os governos agiram no sentido de reanimar um sistema em regime de crescimento letárgico à base de crescente endividamento público e privado.

A descrição do boom é a mesma: a expansão creditícia, impulsionada pela redução das taxas de juros, foi de tal ordem que a relação entre dívida hipotecária e renda disponível saltou de 71\%, em 2000, para 103\%, em 2005. Para Kliman, o que caracteriza o boom imobiliário como bolha especulativa é precisamente o fato de que, de 2000 a 2005, a renda pessoal, depois dos impostos, tenha crescido $35 \%$ enquanto o preço das casas triplicou no mesmo período. Assim, a capacidade de pagar, que depende, em última análise, da produção de novo valor, mostrou-se crescentemente incapaz de fazê-lo, especialmente quando a queda do preço das casas bloqueou qualquer possibilidade de refinanciamento (Kliman 2008, p. 4-5).

\section{Crítica às várias interpretações}

Dos Santos argumenta que, no caso do crédito à força de trabalho, a rationale para obtenção de juros é de muito maior complexidade quando comparada ao crédito direcionado ao circuito do capital industrial (dos Santos, p. 18). Essa observação parece inconsequente uma vez que, do ponto de vista dos bancos, o empréstimo de dinheiro deve realizar $D-D$ ', qualquer que seja o agente de absorção do crédito. Para ele, os bancos entram na relação com a força de trabalho numa posição de vantagem (p. 19), situação na qual podem extorquir ganhos acima da média.

A interpretação de dos Santos e de Lapavitsas foi criticada recentemente por Fine (2009). A principal argumentação de Fine é a de que, ao considerar o valor da força de trabalho como dado, o crédito bancário à força de trabalho, e o correspondente custo em juros, deixa de ter qualquer papel na determinação do valor da força de trabalho; os juros passam a ser uma mera dedução daquele valor. Fine não é muito claro, mas parece estar sugerindo que a mudança no valor da força de trabalho advém de duas modificações coligadas, quais sejam, a mudança no padrão de consumo e na forma de sua aquisição, modificações no bojo das quais os juros deveriam compor o novo valor da força de trabalho; caso contrário esta última teria o seu preço sistematicamente reduzido abaixo do valor. Quanto aos lucros anormais que estariam realizando os bancos em sua relação de crédito com os trabalhadores, dos Santos e Lapavitsas argumentam que eles se derivam do fato de a força de trabalho não ter fontes alternativas de financiamento com as 
quais barganhar as condições de crédito. $\mathrm{O}$ fato de contarem com uma fonte única de acesso ao financiamento os expõe a condições abusivas que aqueles autores denominam de expropriação financeira. Aqui surge o problema de saber se a abolição das condições de crédito abusivas aboliria também a expropriação. De fato, Lapavitsas enfatiza a assimetria de informação e de poder entre bancos e famílias em contraste com a relação de igualdade entre bancos e empresas. $\mathrm{O}$ conceito de expropriação financeira fica obscurecido: afinal, a expropriação financeira se refere a um $\Delta j$ ' advindo das condições mais vantajosas de que gozam os bancos em sua relação com as famílias?

Sobre esse aspecto da análise, Fine também aponta a inconsistência de que os lucros anormais se mantiveram por muito tempo sem que tenham induzido a entrada de novas formas de crédito que pudessem tê-los reduzido a um lucro normal. Mais interessante ainda é a observação de que as proposições de Lapavitsas e dos Santos não se assentam na análise do crédito tal como desenvolvida por Marx. De fato, os autores não se ocupam em deslindar a simbiose entre acumulação monetária e acumulação real tal como realizada por Marx nos capítulos homônimos do terceiro livro d'O Capital. A superestrutura teórica da expropriação financeira, apesar de insatisfatória, não é ociosa do ponto de vista da dinâmica da crise, uma vez que explica o processo de incorporação em massa de famílias assalariadas à engrenagem do consumo a crédito e sua condução à posterior insolvência.

A análise de Lapavitsas apresenta inúmeros problemas conceituais. É verdade que a expropriação financeira é um fenômeno da circulação, mas Lapavitsas não analisa separadamente os dois aspectos da circulação envolvidos na relação entre bancos e tomadores individuais de crédito. Essa relação pode ser representada da seguinte forma:

$$
D-D-M \ldots . . F T-D-D^{\prime}
$$

na qual se pode notar que a força de trabalho compra mercadorias $(D-M)$ antes de ter vendido a sua. Após a transferência do dinheiro do banco para o indivíduo, o dinheiro funciona como meio de circulação com o qual a força de trabalho compra a mercadoria $\mathrm{M}$. Isso significa que a força de trabalho deverá vender para poder pagar. A venda da força de trabalho não mais se efetua para comprar, mas, sim, para pagar. A financeirização do consumo produz uma mudança na função da venda da força de trabalho. Essa é a razão pela qual, na segunda fase, após a venda da força de trabalho, o dinheiro funciona como meio de pagamento da mercadoria adquirida na operação de transferência $D-D$. Que mercadoria é essa? A resposta a essa pergunta ilumina a natureza da assimetria da relação. A mercadoria que a força de trabalho adquire é mero dinheiro. A força de trabalho compra o uso do dinheiro pelo seu preço $D^{\prime}-D=$ juros, mas não o adquire enquanto capital. $\mathrm{O}$ 
banco, por sua vez, vende o dinheiro enquanto mercadoria-capital cujo valor de uso é a produção de lucro, precisamente a diferença $D^{\prime}-D$ que, ao contrário da divisão a que está sujeita na relação com o capital produtivo, é toda embolsada na forma de juros bancários. Essa é a assimetria objetiva subjacente à relação banco/ tomador de empréstimo individual. Não se trata de uma assimetria de informação ou de poder, mas de uma assimetria de circuitos: a função do capital a juros de um lado e, de outro, o circuito do consumo individual financiado. Emprestado como capital, o dinheiro deve retornar acrescido dos juros, independentemente de qual tenha sido a fonte de demanda pelo crédito.

Contrariamente ao que sugere Lapavitsas, a demanda dos indivíduos não é por meio de pagamento, mas por meio de circulação, meio de compra ${ }^{12}$. Se na segunda transferência $D-D$ ' o dinheiro funciona como meio de pagamento, então não pode ser verdade que a expropriação financeira "no que se refere à renda pessoal, mobiliza fluxos já existentes de dinheiro e valor" (p. 40) simplesmente porque o trabalhador vende a força de trabalho para pagar e, portanto, deverá produzir o equivalente ao valor de sua força de trabalho antes de receber o seu salário. Mas tudo fica ainda mais confuso quando Lapavitsas afirma que, devido ao caráter sistemático que adquire, a expropriação financeira, ainda que seja um fenômeno da esfera da circulação, comporta um aspecto de exploração (p. 40). Restaria, por fim, saber como essa expropriação pode aumentar os lucros da classe capitalista como um todo ${ }^{13}$. Se por um lado o consumo à base do crédito aumenta os lucros dos setores que ofertam os produtos demandados, por outro diminui o poder de compra na exata medida dos salários expropriados na forma de juros bancários. O lucro bancário imediatamente se acresce, mas o lucro industrial aumenta somente para os setores envolvidos na cadeia de produção dos produtos que constituem o fundamento da bolha especulativa.

O principal problema teórico das visões estagnacionistas é a postulação de um desequilíbrio permanente entre oferta e demanda. Em contraposição à contínua redução do consumo na renda, a produção de bens de consumo segue seu curso imperturbado, causando excesso de capacidade e redução de investimentos. A redução do nível de investimentos não parece operar como um mecanismo de restabelecimento da proporcionalidade entre demanda e capacidade produtiva, como se o efeito da defasagem inicial pudesse se reproduzir indefinidamente.

É importante notar que autores como Foster e Magdoff se valem muito mais de Keynes do que de Marx. Os conceitos proeminentes são tipicamente

(12) "La dependencia de los particulares respecto del dinero como medio de pago (no solo como medio de cambio) ha ido creciendo a medida que la provisión del sector público se retiraba de las esferas de la vivienda, las pensiones, el consumo, la educación, etcétera" (Lapavitsas, 2009, p. 43, grifos meus).

(13) "Mientras que la acumulación real ha tenido resultados más bien pobres, la clase capitalista ha encontrado nuevas fuentes de ganancia en mecanismos financieros modernizados" (Lapavitsas, 2009, p. 34). 
keynesianos, a saber: problemas de demanda efetiva ligados à diminuição da propensão marginal dos capitalistas a consumir, o equilíbrio de desemprego como estado natural da economia capitalista, a transformação de Keynes num teórico do ciclo da economia capitalista, transformação, essa, efetuada por Minsky, e assim por diante. Exemplo marcante da hipertrofia de Keynes entre os marxistas é a referência de Foster e Magdoff (p. 16) à teoria dos dois preços de Keynes, posteriormente formalizada por Minsky na teoria pós-keynesiana do investimento. Os autores não parecem perceber que a duplicação entre investimento produtivo e títulos de direito sobre os ganhos desses investimentos produtivos é a própria teoria do capital fictício de Marx no que diz respeito ao caso específico das ações, mas que não se limita a elas. Ademais, parecem desconsiderar a análise realizada por Marx na qual a fase expansiva do ciclo gera, necessariamente, uma febre especulativa com base naqueles papéis.

A incongruência que encontramos na análise de Husson é parecida com a incongruência subconsumista, uma vez que se sustenta sobre a noção de que o produto social cresce mais rápido do que as fontes de demanda que são os salários mais os investimentos. Ademais, essa diferença é crescente, pois se reflete numa diferença crescente entre lucro realizado e lucro reinvestido. No entanto, como se pode realizar o lucro sobre a base de uma constante divergência entre produção e demanda? Se a divergência é ex-post, não deveria ela causar um reajuste da capacidade produtiva? E como podemos ter ao mesmo tempo uma alta substantiva da lucratividade e falta de alternativas rentáveis devido à contração da demanda dos trabalhadores?

Quanto à sua crítica à lei da tendência de queda da taxa de lucro, Husson trata a contra tendência como lei contrária e de mesmo status que a lei principal. Mas ele próprio cita uma passagem relevante a esse respeito na qual Marx afirma que "as mesmas causas que engendram a redução da taxa de lucro moderam a realização dessa tendência", afirmação, essa, que revela o caráter mitigador das contra tendências, uma vez que são dependentes da tendência principal. $\mathrm{Na}$ verdade, para Husson, não opera nem mesmo a ideia básica, entre marxistas, de que a lei de tendência de queda da taxa de lucro se refere à tendência ao decréscimo da taxa máxima de lucro, $L / c$, onde $L=v+m$ é o trabalho novo realizado sobre os meios de produção e $c$ é o valor daqueles meios de produção denominado capital constante. Isso porque, para ele, nem a composição orgânica precisa necessariamente crescer. Sua direção é indeterminada. Aqui temos um problema conceitual. A composição orgânica enquanto reflexo da composição técnica, ou seja, calculada a preços relativos constantes entre meios de produção e meios de consumo, deve necessariamente crescer, uma vez que se conceda que a composição técnica aumente progressivamente. Assim, quando ele se refere à composição orgânica, devemos ler composição de valor, pois esta, sim, pode 
divergir da composição técnica, seja devido a mudanças nos valores relativos entre meios de produção e meios de consumo, seja devido a mudanças no salário real ${ }^{14}$. A lei de queda tendencial da lucratividade apresentada n'O Capital é derivada com base na composição orgânica justamente porque a composição orgânica espelha a composição técnica, e não haveria nenhuma razão para supor que o índice de preços dos meios de produção teria um comportamento de longo prazo diferente do índice de preços dos meios de consumo. A análise empírica só pode se valer da composição de valor, mas esta flutua ao redor da composição orgânica. Se a composição de valor divergisse da composição orgânica por períodos prolongados, isso significaria que a diminuição do valor da força de trabalho seria sistematicamente menor do que a diminuição da quantidade de capital constante por trabalhador. Mas isso seria impossível. O aumento da quantidade de capital constante por trabalhador é um indicador de aumento da produtividade. É, portanto, um processo organicamente relacionado à diminuição no ritmo de crescimento do emprego, fato que teria como consequência uma contenção dos salários. A sua conclusão de que a lei tendencial é mal formulada, pois não permite considerar o papel decisivo da produtividade (p. 18), deveria ser acompanhada pela conclusão de que a lei mais importante da economia política, para Marx, é ao mesmo tempo seu erro mais grave.

No que tange a teoria de Kliman, é preciso que se diga que sua proposição apresenta uma teoria alternativa à de Marx. A taxa incremental de lucro, $\Delta m / \Delta C$, também tem que cair, pois a composição $c / v$ aumenta com o tempo. De fato, para Marx, a tendência de queda da taxa de lucro deve-se ao aumento da composição orgânica do capital, enquanto, para Kliman, ela se deve ao fato de que a taxa de lucro incremental tende a dominar a taxa de lucro efetiva à medida que a expansão dissipa a energia acumulada com a destruição de capital na crise precedente. A menos que o capital sofra uma nova desvalorização através de uma crise econômica, a taxa de lucro efetiva tenderá à taxa de lucro incremental. Ademais, a massa de mais-valia deve estagnar em algum momento, coisa impossível no esquema de Kliman, uma vez que a taxa de lucro incremental é positiva e constante $^{15}$.

\section{Conclusões}

Este trabalho procurou analisar criticamente algumas das mais importantes contribuições relativas ao caráter da presente crise. A escola da Monthly Review

(14) Ver Shaikh (1990, p. 306).

(15) Na sua teoria de crise de superacumulação, Shaikh (1991) mostra que a massa de mais-valia deve estagnar quando o efeito positivo do aumento do estoque de capital sobre os lucros for menor que o efeito negativo da diminuição da taxa de lucro. Artigo recente de Giussani (2010) apresenta uma discussão crítica das proposições de Kliman. 
apresenta uma evolução conceitual que mantém o mesmo resultado: a tendência do capitalismo à estagnação, agora em simbiose com a financeirização. A primeira contribuição de Sweezy (1973) advogava que a produção de meios de consumo tendia a crescer mais rapidamente do que o crescimento da demanda de meios de consumo. Isso se devia ao fato de que a produção de meios de consumo dependia da produção de meios de produção. $\mathrm{O}$ emprego de meios de produção aumenta a produção de meios de consumo, mas não aumenta a massa salarial na mesma proporção. Ao contrário, o gasto com salários cresce mais devagar. A capacidade de produzir meios de consumo cresce mais rapidamente do que a demanda de consumo dos trabalhadores, enquanto, por outro lado, o consumo dos capitalistas diminui à medida que os lucros aumentam. Essa visão subconsumista que se aplica ao departamento produtor de meios de consumo é estendida, em Monopoly Capital, para os dois departamentos da produção social, o departamento produtor de meios de consumo e o departamento produtor de meios de produção. Com o fim da concorrência de preços, o excedente tende a crescer acima das possibilidades de investimento, causando excesso de capacidade. A tese da tendência à estagnação ganha reforço na existência de excesso crônico de capacidade e na consequente diminuição do ritmo de acumulação. A visão subconsumista é reiterada por Sweezy, em 1994, no seu artigo The Triumph of Finance Capital e complementada em seu artigo Monopoly Capital After 25 years, no qual faz uma reflexão crítica sobre as lacunas do Monopoly Capital, entre as quais os desenvolvimentos financeiros não previstos naquele livro. As recentes contribuições de Foster e Magdoff repetem ipsis literis os mesmos argumentos e, portanto, estão sujeitas às mesmas críticas já desenvolvidas a respeito da visão subconsumista. Delas, é preciso reiterar aquela que se refere ao vício subconsumista - seja na versão inicial, seja na versão desenvolvida para os dois departamentos - de postular um desequilíbrio permanente entre crescimento da capacidade e crescimento da demanda, desequilíbrio, esse, em total desavença com a análise da reprodução ampliada desenvolvida por Marx no segundo livro d'O Capital. Ademais, é patente que Magdoff e Foster não desenvolvem uma análise teórica a partir das contribuições do próprio Marx. A relação entre excesso de lucros relativamente às possibilidades de investimento não é articulada com o desenvolvimento do crédito ao consumo. Ao contrário, é a política econômica que aparece em primeiro plano, reduzindo os juros assim que a implosão de uma bolha faz voltar à tona o espectro da crise (p. 50). Por fim, Foster e Magdoff chegam a conclusões parecidas ao conceito de expropriação financeira de Lapavitsas e dos Santos: o aumento do endividamento familiar e os processos especulativos acabam por extrair mais excedente da população e, portanto, se constituem em mecanismos de exploração dos trabalhadores e das classes médias inferiores (p. 61). 
Para efeito de melhor visualização dos resultados obtidos apresentamos, no quadro abaixo, as teorias examinadas e as principais críticas desenvolvidas.

Quadro 1

Interpretações da crise e críticas principais

\begin{tabular}{|c|c|c|}
\hline & Causas da crise & Crítica \\
\hline $\begin{array}{l}\text { Costas Lapavitsas } \\
\text { Paulo dos Santos }\end{array}$ & $\begin{array}{l}\text { Independização financeira das } \\
\text { grandes corporações em relação } \\
\text { ao crédito bancário levou } \\
\text { bancos a redirecionarem os } \\
\text { fluxos de crédito para as } \\
\text { famílias como fonte alternativa } \\
\text { de lucros na forma de } \\
\text { expropriação financeira face a } \\
\text { salários estagnados. }\end{array}$ & $\begin{array}{l}\text { A teoria da expropriação } \\
\text { financeira implica que os juros } \\
\text { são uma subtração do valor da } \\
\text { força de trabalho e, desse modo, } \\
\text { a teoria se assenta sobre a } \\
\text { hipótese de que a força de } \\
\text { trabalho está sendo paga } \\
\text { sistematicamente abaixo do seu } \\
\text { valor. }\end{array}$ \\
\hline Michel Husson & $\begin{array}{l}\text { Aumento da taxa de exploração } \\
\text { da força de trabalho e da taxa de } \\
\text { lucro sem aumento da taxa de } \\
\text { acumulação redirecionou a } \\
\text { mais- valia para as finanças } \\
\text { como forma de gerar fontes } \\
\text { alternativas de demanda. }\end{array}$ & $\begin{array}{l}\text { O aumento da taxa de } \\
\text { exploração teria enfraquecido a } \\
\text { demanda efetiva e tornado } \\
\text { inviável a acumulação da mais- } \\
\text { valia. Mas Husson não explica } \\
\text { como esse processo pode se } \\
\text { reiterar continuamente. }\end{array}$ \\
\hline $\begin{array}{l}\text { John Bellamy Foster } \\
\text { Fred Magdoff }\end{array}$ & $\begin{array}{l}\text { Monopólios lucrativos não } \\
\text { podem reinvestir o excedente } \\
\text { para não deprimir suas margens } \\
\text { de lucro, de modo que a mais- } \\
\text { valia busca valorizar-se através } \\
\text { de aplicações no mercado } \\
\text { financeiro, gerando ondas de } \\
\text { especulação. }\end{array}$ & $\begin{array}{l}\text { A produção de meios de } \\
\text { consumo não é proporcional ao } \\
\text { investimento, mas apenas ao } \\
\text { investimento em meios de } \\
\text { consumo, e não há motivo pelo } \\
\text { qual a produção de meios de } \\
\text { consumo não possa se adaptar } \\
\text { ao nível da demanda. }\end{array}$ \\
\hline Andrew Kliman & $\begin{array}{l}\text { Sem destruição de capital, a } \\
\text { taxa de lucro efetiva não } \\
\text { consegue aumentar acima da } \\
\text { taxa de lucro de longo prazo, } \\
\text { que é baixa, e mantém a } \\
\text { economia em regime de letargia } \\
\text { de modo que os governos } \\
\text { tentam compensar este fato, } \\
\text { facilitando o crédito e criando } \\
\text { bolhas especulativas. }\end{array}$ & $\begin{array}{l}\text { A análise diverge da visão de } \\
\text { Marx, para quem a redução da } \\
\text { taxa de lucro resulta do } \\
\text { aumento de c/v. Ademais, para } \\
\text { Marx, a massa de lucro deve ser } \\
\text { levada à estagnação, fato que } \\
\text { não pode ocorrer na teoria de } \\
\text { Kliman, já que sua taxa de lucro } \\
\text { de longo prazo é positiva. }\end{array}$ \\
\hline
\end{tabular}

A análise das várias contribuições revela linhas divisórias interessantes. Por um lado, temos aquelas para as quais a crise teve como fundamento o afluxo dos lucros da produção para as finanças, como é o caso das interpretações de Husson e da dupla Foster/Magdoff. Por outro, temos aquelas para as quais o aumento do crédito de consumo foi resultado de uma reestruturação dos fluxos de 
crédito das empresas, cada vez mais autônomas no mercado de dinheiro, às famílias assalariadas, cada vez mais dependentes do financiamento bancário. Essa linha divisória reflete a importância que o primeiro grupo adjudica à diminuição do ritmo de crescimento vis-à-vis os teóricos da School of Oriental and African Studies. Finalmente, temos a visão de Kliman para o qual a causa do baixo ritmo de crescimento durante o período neoliberal foi a baixa taxa de lucratividade. A tentativa do governo americano de compensar o baixo crescimento através do estímulo ao crédito teria levado ao boom imobiliário e à bolha especulativa.

A análise revela também que a hipertrofia do uso de Keynes entre marxistas, mesmo quando o aparato conceitual de Marx é profícuo para o entendimento do capitalismo moderno, faz com que, face à exiguidade do desenvolvimento teórico imediatamente disponível, marxistas importantes, como Moseley $^{16}$, por exemplo, renunciem rapidamente à possibilidade de análise da crise com base nos conceitos de Marx e o declarem peremptoriamente um teórico menor do sistema financeiro capitalista. Como sugerido anteriormente, os processos especulativos são parte integrante da parte superior do boom na visão de Marx. É precisamente a entrada em cena dessa fase que dá aos momentos que precedem o crash a aparência de vigor que ilude os observadores e produz previsões que logo se mostram desprovidas de fundamentos.

\section{Referências bibliográficas}

BARAN, Paul; SWEEZY, P. Monopoly capital: an essay on the American economic and social order. New York and London: Modern Reader Paperbacks, 1968.

BRENNER, R. What is good for Goldman Sachs is good for America: the origins of the current crisis. Los Angeles, CA: UCLA. Center for Social Theory and Comparative History, Apr. 18, 2009. (Prólogo da tradução para o espanhol do livro Economic of Global Turbulence, maio 2009).

DOS SANTOS, Paulo. At the heart of the matter: household debt in contemporary banking and the international crisis. Research on Money and Finance, Discussion Paper, n. 11, May 11, 2009. Disponível em: www.soas.ac.uk/rmf.

FINE, B. Financialisation, the value of labour power, the degree of separation, and exploitation by banking. London: SOAS, Apr. 2009.

FOSTER, John Bellamy; MAGDOFF, Fred. The great financial crisis. New York: Monthly Review Press, 2009.

(16) "The best theorist of the capitalist financial system is Hyman Minsky, not Karl Marx. The current crisis is more of a Minsky crisis than a Marx crisis. I am not saying that we should throw away Marx (obviously), but rather that we should supplement Marx with Minsky, especially for analysis of the modern capitalist financial system". 
GIUSSANI, Paolo. Il movimento del saggio del profitto secondo Andrew Kliman. Milan, May, 2010. (Primeira versão provisória).

HUSSON, Michel. La hausse tendancielle du taux de profit. Jan. 2010. Disponível em: http://hussonet.free.fr/cricoco.htm.

. Marxists on the capitalist crisis: 7. Michel Husson - A systemic crisis, both global and long lasting. Jul. 2008. Disponível em: http://www.workersliberty.org.

JOSHUA, I. Notes sur la trajectoire du taux de profit. Contretemps, Oct. 2009. Disponível em: http://contretemps.eu.

KLIMAN, Andrew. 'The destruction of capital' and the current economic crisis. Jan. 15, 2009. Disponível em: www.socialistdemocracy.org.

17, 2009.

. On the roots of the current economic crisis and some proposed solutions. Apr.

. The persistent fall in profitability underlying the current crisis: new temporalist evidence. $2^{\mathrm{a}}$ versão. Oct. 17, 2009.

Masters of words: a reply to Michel Husson on the character of the latest economic crisis. Feb. 19, 2010.

. A crisis for the centre of the system. Oct. 2008.

ITOH, Makoto. On the historical significance and the social costs of the sub-prime financial crisis: drawing on the Japanese experience. Research on Money and Finance, Discussion Paper, n. 7, Mar. 15, 2009. Disponível em: www.soas.ac.uk/rmf.

LAPAVITSAS, Costas. El capitalismo financiarizado. Madrid: Maia Ediciones, 2009.

. Costas Lapavitsas interview: the credit crunch. International Socialism. Disponível em: http://www.isj.org.uk/index.php4?id=395.

MOSELEY, Fred. US home mortgage crisis: how bad will it be? Causes and solutions. 2008. Mimeografado.

SHAIKH, A. An introduction to the history of crises theories. In: URPE (Org.). U.S. capitalism in crisis. Urpe-Union for Radical Political Economics, 1978. p. 219-240.

Organic composition of capital. In: EATWELL, J.; MILGATE, M; NEWMAN, P. (Ed.). Marxian economics - The New Palgrave. New York-London: W. W. Norton \& Company, 1990.

. Valor, acumulación y crisis. Ensayos de economia política. Bogotá: Tercer Mundo Editores, 1991.

SWEEZY, P. Teoria do desenvolvimento capitalista. Rio de Janeiro: Zahar Editores, 1973.

YAFFE, D. Why the organic composition of capital must rise with accumulation. Disponível em: www.marxists.org/subject/economy/authors/yaffed/1972/note.htm. 